\title{
Edgar Allan Poe: um poeta autossimbólico
}

\author{
Edgar Allan Poe: a self-symbolic Poet
}

\author{
Sarug Dagir Ribeiro* \\ Universidade Federal de Minas Gerais \\ Belo Horizonte, Minas Gerais, Brasil \\ Fábio Roberto Rodrigues Belo** \\ Universidade Federal de Minas Gerais \\ Belo Horizonte, Minas Gerais, Brasil
}

\begin{abstract}
Resumo: Por meio da análise de trechos de alguns contos e do exame da psicobiografia de Poe, aquela realizada pela psicanalista francesa Marie Bonaparte, constatar-se-á que os mecanismos que presidem a transformação dos pensamentos do poeta americano em imagens são semelhantes aos mecanismos de formação dos sonhos como a condensação, o deslocamento e os recursos figurativos. Assim, a criação literária de Poe revela sob o modo fictício a satisfação dos seus desejos infantis, arcaicos e inconscientes. Essa trajetória abre caminho para se pensar tanto no caráter autossimbólico dos seus textos ficcionais como também circunscreve a sua psicobiografia como um estudo que abre caminho para se pensar o transvasamento do inconsciente no trabalho de elaboração literária.
\end{abstract}

Palavras-chave: Edgar Poe; inconsciente; literatura.

\begin{abstract}
Through the analysis of excerpts from some tales and the examination of Poe's psychobiography, that performed by the French psychoanalyst Marie Bonaparte, it will be found that the mechanisms that govern the transformation of the American poet's thoughts into images are similar to the mechanisms of formation of dreams such as condensation, displacement and figurative resources. Thus Poe's literary creation reveals in a fictional way the fulfillment of his childish, archaic, and unconscious desires. This trajectory opens the way to think about the self-symbolic character of his fictional texts and also circumscribes his psychobiography as a study that opens the way to think about the unconscious overflow in the work of literary elaboration.
\end{abstract}

Keywords: Edgar Poe; unconscious; literature.

\section{INTRODUÇÃO}

Dentre todas as literaturas estrangeiras de grande circulação no Brasil, a obra de Edgar Allan Poe é sem dúvida uma das mais mórbidas e sombrias. Vista por uma ótica superlativa como sendo o mais elevado expoente do gênero ficcional envolvendo terror e morte. O estudo psicobiográfico realizado por Bonaparte (1933a; 1933b; 1958) estabelece parâmetros de análise sobre esse terror liberado nos contos de Poe. Segundo a autora, o mesmo está relacionado a uma profunda ansiedade inconsciente, muitas vezes confrontada com "[...] impulsões sádicas antigas, ligadas à morte da sua mãe e esposa" (BONAPARTE, 1932a, p. 681, 
tradução nossa). E o poeta americano encontrou nas tramas e nas personagens que criou uma maneira de expressar a qualidade e a intensidade desses afetos. Essa pesquisa permite refletir sobre a elaboração da obra literária de Poe utilizando o método psicanalítico e é razoável supor que seus contos constituem uma tela do conteúdo do seu inconsciente projetado, cujo conteúdo envolve culpa, incesto, assassinato e conflitos edípicos.

O desenvolvimento desse trabalho se divide da seguinte maneira: na primeira seção apresentaremos em linhas gerais as interpretações psicanalíticas de Bonaparte (1933a; 1933b; 1933c; 1932a; 1932b; 1958) sobre a personalidade e a obra de Poe, bem como algumas das principais controvérsias e críticas às suas hipóteses, recolocála em questão no debate Lacan versus Derrida em torno da "Carta Roubada". Na segunda seção, examinamos as considerações bonaparteanas que postulam que os mecanismos gerais de elaboração da obra literária em Poe são similares aos mecanismos de formação de um sonho ruim ou pesadelo. Na terceira e última seção apresentamos alguns aspectos da terminologia e do simbolismo na obra de Poe, em que o macabro, o sombrio, a necrofilia e o sadismo são fundamentais para o efeito universal dos seus contos que tocam tão a fundo a universalidade dos sentimentos dos leitores.

\section{POE NO DIVÃ DE BONAPARTE}

O trabalho de Bonaparte (1933a; 1933b; 1958) é uma pesquisa monumental dentro da perspectiva das relações entre psicanálise e literatura, tomando como objeto a vida e a obra de Edgar Allan Poe. Seu nível de exigência obrigou a autora a efetuar numerosas pesquisas que em parte ela mesma pode assumir sozinha, outras vezes contou com a ajuda de amigos. O período de redação dessa pesquisa durou aproximadamente oito anos (BERTIN, 1989) e dentre as inúmeras colaborações contou com a de seu colega e mestre Sigmund Freud que oportunamente escreveulhe um delicioso prefácio em que afirma: "Graças a seu trabalho de interpretação, compreende-se que a presente combinação de características da obra foram condicionadas pela personalidade do autor" (FREUD, 1933, p. VII, tradução nossa). Esse estudo é composto de três volumes, sendo os dois primeiros tomos publicados em 1933 e o terceiro e último em 1958, totalizando quase 900 páginas no total. Alguns críticos apontam que o interesse de Marie Bonaparte pela obra de Poe se deve ao fato que no verão de 1901, então, com 19 anos de idade, seu pai, príncipe Roland Bonaparte, recomenda-lhe a leitura de Histoires extraordinaires, tradução de Baudelaire de 1856. Assim, ao ler no conto Ligeia a descrição de um cadáver vivente, ela é tomada de um medo terrificante (BERTIN, 1989).

Anos mais tarde, com quarenta e três anos de idade e em análise pessoal com Sigmund Freud, ela tenta reler a obra de Poe. Desse modo, busca explicar por que 
anos anteriores ela tinha sentido aquele medo paralisante. Por conseguinte, ela descobre algumas coincidências entre a sua própria vida e a do poeta americano, que do mesmo modo que ela, tinha perdido sua mãe ainda criança por causa da tuberculose, ele aos três anos de idade e ela, com três meses de vida. "Esta similitude tem provavelmente um papel decisivo no interesse de Marie Bonaparte por Edgar Poe" (AMOUROUX, 2012, p. 122, tradução minha). Pois, por meio das novelas do autor, ela será confrontada com seu medo edípico do retorno da mãe morta cuja morte ela acreditava ter causado com seu próprio nascimento. De fato, a representação da mãe morta constitui o principal ponto na sua análise com o pai da psicanálise, levando-a a aceitar que: "a mãe morta, aquela com que eu me identifiquei, permanece inconsciente, como um conceito e uma imagem. Ela constitui uma representação inconsciente integral" (BONAPARTE, 1952a, p. 98, tradução minha). Por conseguinte, como resultado do tratamento analítico, bem como dos ensinamentos de psicanálise por meio dos quais ela sempre tomava muitas notas (BOURGERON, 1997), esboça o projeto de escrita de um livro sobre Poe. Esse livro de três volumes começa pelo estudo da biografia e em seguida passa para a análise psicanalítica dos poemas e contos (BONAPARTE, 1933a). Na parte intitulada "Os ciclos da mãe" (BONAPARTE, 1933b), a autora coloca em evidência o papel-chave da figura materna nos contos do poeta. Demonstra como as personagens lânguidas, etéreas e macabras que povoam os seus contos são o protótipo da visão moribunda da própria mãe. Poe teria poetizado em suas personagens femininas como Berenice, Morella, Ligeia, Madalena, Eleonora e outras, a necrofilia contemplativa que ele vivenciou no leito de morte de sua mãe e depois de sua própria esposa. Na parte intitulada "Os ciclos do pai", Bonaparte (1958) explora o lugar do pai na obra de Poe, por um lado, o pai biológico que o abandonou, e por outro lado, o pai adotivo, que muitas vezes fora objeto de raiva por parte do pequenino Poe quando criança, isso devido à avareza e ao sucesso profissional e financeiro desse padrasto. A autora destaca que os personagens homens na obra de Poe são geralmente como uma encarnação do mal, da perversão, do crime. Em termos psicanalíticos, é atribuído à presença de um superego sadicamente cruel em Poe. Nesse ponto, consideramos válidas as considerações de Bakhtin (2003) sobre o autor e a personagem, em que "a luta do artista por uma imagem definida da personagem é, em um grau considerável, uma luta dele consigo mesmo" (p. 5). Bonaparte (1932a) vê uma lei psicológica sedimentada na elaboração da obra literária, em suas palavras: "as obras literárias e artísticas dos homens se revelam e se edificam a mais íntima psicologia" (p. 649, tradução minha). Segundo a autora, podemos constatar uma forte semelhança entre a elaboração do sonho e a criação literária em Poe, na qual os desejos infantis, arcaicos, inconscientes do artista, mais ou menos disfarçados, encontram-se e se satisfazem na ficção. Assim, da mesma maneira que o sonho, a obra literária é uma realização do desejo (inconsciente). "Muitas produções 
de cuja execução no sonho podíamos nos admirar, agora, não cabe mais atribuir ao sonho, mas sim, ao pensamento inconsciente que também trabalha durante o dia" (FREUD, 1900/2017, p. 640). Conforme esse raciocínio, deduz-se que os personagens de Poe retratam as raízes arcaicas e profundas da própria personalidade do escritor.

Portanto, através de diversos processos de elaboração, os componentes psíquicos tendem a se encarnar nos diversos personagens de modo sombrio e macabro, em que as composições narrativas lembram os tormentos de um agonizante pesadelo marcado pelo auxílio das potências sádicas e obscuras da psique do poeta. Podemos dizer que o grande manancial de inspiração de Poe foi suas fontes infantis mais profundas, ou seja, seu inconsciente. Nessa direção em explicar pela biografia do autor sua obra, Bakhtin (2003) afirma que não se deve "negar a possibilidade de comparar de modo cientificamente produtivo as biografias do autor e da personagem e suas visões de mundo" (p. 9). De modo geral, podemos constatar nos três volumes que constituem a psicobiografia de Poe (BONAPARTE, 1933a; 1933b; 1958) um estudo embasado de maneira eficiente na psicanálise e que possui atributos produtivos tanto para a crítica literária quanto para a análise estética.

Desse modo, em decorrência desta laboriosa pesquisa, a autora ainda publica dois artigos (BONAPARTE, 1932a; 1932b) em que aborda a situação inicial de pobreza de Poe. A autora também sintetiza seus pontos de vista sobre o tema da elaboração e da função da obra literária (BONAPARTE, 1932b), em seguida, disserta sobre a personalidade de Edgar Poe (BONAPARTE, 1933c) relacionando-a ao sadismo e à necrofilia, chamando-o de poeta sado-necrófilo.

Esse gênero de pesquisa no vasto corpus bonaparteano é do tipo "estudos psicobiográficos" (AMOUROUX, 2012, p. 123), método de investigação psicanalítica iniciado com muita precisão pelo próprio pai da psicanálise, por exemplo, a análise que faz do delírio e dos sonhos na "Gravida" de W. Jensen (FREUD, 1907[2015]), em que demonstra interesse pela forma como os escritores se utilizam do sonho na produção literária; no seu famoso estudo sobre Leonardo da Vinci (FREUD, 1910[1980]), em que, tomando a biografia e as obras do artista italiano e com base em seus conhecimentos dos mecanismos psíquicos, levanta a tese da etiologia da homossexualidade masculina como sendo ligada à ausência do pai e à "demasiada ternura por parte da mãe" (p.105).

Outro estudo dessa natureza é a análise que ele fez da autobiografia de Schreber (FREUD, 1911/1974) consolidando as explicações sobre a psicose paranoide, atribuindo-lhe uma relação íntima e invariável com desejos e fantasias homossexuais inconscientes. Deve-se, de modo geral, por um lado, reconhecer os limites do que a psicanálise pode conseguir no campo da biografia e da análise de obras literárias e artísticas, como, por outro lado, tomar uma perspectiva crítica (MANDIL, 2000) das relações entre literatura e psicanálise. Desde Kant, tomar uma 
perspectiva crítica sobre algo é reconhecer seus limites. Pois, ainda hoje há o espanto que Poe provoca nos seus leitores, "cada vez mais inaptos a consumir produtos que resistem à massificação" (MANDIL, 2003, p. 271). São obras que convocam o crítico a esmiuçá-las, e o psicanalista, a vacilar na posse da verdade imutável da nossa relação com a linguagem.

Essas hipóteses sobre o entendimento da obra de Poe por Bonaparte (1933a; 1933b; 1958) foram objetos de controvérsias e largamente criticadas por seus contemporâneos. Lacan (1998), num seminário sobre o conto "A carta roubada" (POE, 2002), tenta ridicularizar a interpretação feita pela autora e julgava tê-la ultrapassado na leitura do texto do poeta americano. Nesse seminário, o foco da perspectiva da análise lacaniana é expor o deslocamento do significante na série significante / significado. Nessa situação, a carta é a instância paradoxal que liga as duas séries e que não está em nenhuma delas. Podemos considerá-la como elemento flutuante, de dupla face, no entanto, "de importância extraordinária na dotação de sentido" (MARCONDES FILHO, 2004, p. 80) justamente porque promove a comunicação dos dois planos. Nesse conto de Poe (2002), o conteúdo da carta jamais é revelado e toda a trama acontece em função do seu deslocamento. Nesse sentido, "Lacan buscava em Poe algo que ficaria de fora das séries numéricas (automatismo de repetição), contudo, condizente com seu ensino naquele momento e da primazia conferida ao simbólico em seu retorno a Freud, acabou por reduzir a carta ao significante" (HENRIQUES, 2017, p. 78).

De acordo com Derrida (2007) a leitura lacaniana "ignora a estrutura formal do texto de Poe" (p. 478), pois, as duas cenas triangulares que o autor isola: os roubos da carta, respectivamente, nos aposentos reais e no apartamento do ministro, reduzem a trajetória da carta a um único trajeto que retorna a um lugar determinável. Ou seja, "em sua tentativa de romper com a leitura psicanalítica de Poe centrada no imaginário, realizada por Marie Bonaparte, Lacan cai no outro extremo fechando-se num formalismo rígido e, a partir daí, estabelece sua própria leitura de Poe, à luz da onipotência do simbólico" (HENRIQUES, 2017, p. 79). Podemos considerar que a leitura lacaniana foi uma análise textual mais simplificadora do que aquela realizada por Marie Bonaparte. A autora coloca o conto "A carta roubada" (POE, 2002) em relação com outros textos do poeta americano, procedimento ao qual Lacan (1998) se furtou. Por outro lado, Tytell (1982) considera a psicobiografia de Poe de Bonaparte (1933a; 1933b; 1958) um exemplo de psicanálise aplicada, entretanto, muito simplista e reducionista. O autor reprova o fato de que a autora projeta sua própria história de vida na sua interpretação sobre a obra do poeta. Ricardou (1967), teórico do novo romance, atribui um tipo de blefe exegético ao trabalho de Bonaparte, pois, segundo ele, a autora aponta com hábil retórica a reivindicação da completude e da universalidade de sua análise com base em interpretações parciais de certos símbolos. Bachelard (1942), num tom menos rude afirma: "Madame Marie 
Bonaparte, na sua minuciosa e profunda análise dos poemas e contos de Edgar Poe, descobre a razão psicológica dominante por detrás deles" (p.63-64). Reconheçemos em Bonaparte uma leitora sagaz de Poe, cujas lições psicológicas acumuladas na sua psicobiografia são notáveis referências nos estudos da relação entre literatura e psicanálise. Nas seções seguintes veremos respectivamente, na presença da literatura de Edgar Poe no Brasil, aspectos da elaboração da obra literária e algumas expressões da eloquência intensa e imagética do artista.

\section{SOBRE A ELABORAÇÃO DA OBRA LITERÁRIA EM POE}

De acordo com a análise de Bonaparte (1933a; 1933b; 1958) o trabalho de elaboração e criação literária de Poe, em graus diversos, ocorre segundo os mesmos mecanismos clássicos que a elaboração dos sonhos (FREUD, 1900[2017]), sejam alguns deles: a condensação, o deslocamento e a figuração. No entanto, a obra literária, diferente do sonho, é um produto do pensamento desperto, o que faz com que as relações lógicas possam subsistir dentre as diversas expressões latentes presentes na obra artística. Ou seja, "[...] a obra literária conta uma certa história coerente e manifesta, mas, ao mesmo tempo uma outra história, secreta e profunda, intromete-se na história superficial. Assim, constitui-se uma trama profunda e subjacente à primeira" (BONAPARTE, 1932a, p. 667, tradução nossa). Do ponto de vista tópico, o aparelho psíquico é constituído pelos sistemas: inconsciente, préconsciente e consciente (FREUD, 1915[1980]). O pré-consciente com a censura é o responsável pela coerência da obra literária, pois, faz o artista escolher ou rejeitar os elementos propostos pela elaboração primária inconsciente (pensamentos latentes), então, elimina-se aquilo que é muito absurdo e muito chocante e estabelece-se novos elos lógicos. Já quanto ao sonho, espera-se que ele seja absurdo e sem coerência.

Segundo Freud (1900[2017]), a elaboração do sonho se serve também dos processos dinâmicos do aparelho psíquico no deslocamento de intensidades psíquicas que, com a ajuda de resíduos colhidos ao longo do dia, como imagens e lembranças visuais e auditivas tomadas aleatoriamente, produzem o pensamento onírico. Esses restos diurnos serão modificados ou distorcidos por meio do trabalho do sonho na condensação, no deslocamento e na figurabilidade. Em outros termos, um pensamento diurno qualquer incita um desejo inconsciente e ajuda a criar um sonho.

O pilar na teoria freudiana do sonho é que se atribui "ao desejo oriundo do infantil o papel de motor imprescindível para a formação dos sonhos" (p. 617), já que todo sonho é a realização de um desejo (inconsciente). Sendo assim, são também os desejos infantis (inconscientes) que constituem o motor de todo processo da elaboração literária (BONAPARTE, 1932a) utilizando, tal como nos sonhos, de: deslocamentos, condensações e possibilidades de figuração. Sobre esses mecanismos podemos dizer que o deslocamento é um dos principais meios para se obter a 
distorção. Então, o conteúdo manifesto não se assemelha ao conteúdo latente, assim o desejo inconsciente subjacente é desse modo distorcido pela censura (préconsciente). Quanto ao processo de condensação, ele se serve de mais de um meio, o principal deles é a produção de pessoas coletivas ou pessoas mistas. Consiste em unir traços de duas ou mais pessoas em uma só. Nos contos de Poe são flagrantes os exemplos de personagens mistas. Por exemplo, no conto Os assassinatos da rua Morgue (POE, 2006), o personagem W. Wilson, por um lado, personifica os ímpetos indomados mais profundos da personalidade de Poe, bem como nas atitudes do personagem como o decifrador de enigmas e criptogramas representa o pesquisador infantil que um dia o pequenino Poe foi na infância. E de outra parte, esse personagem também reúne traços do pai, castrador e punidor. Já a personagem feminina, a velha dama assassinada, reúne traços da mãe e da esposa de Poe. As representações do quarto, ora com as portas fechadas, ora com as portas abertas, simbolizam também a figura da mulher, da mãe e da esposa violadas, mortas, num tipo de dispersão para outros objetos da entidade materna e feminina "num grande oceano comum de simbolismo" (BONAPARTE, 1932a, p. 664). Já a figurabilidade remete aos recursos à imagem e aos traços visuais. Nisso ocorre a transformação direta de uma imagem em outra numa sucessão dos elementos, em consequência: "lugares são tratados frequentemente como pessoas" (FREUD, 1900/2017, p. 343), ou ainda, uma pessoa ou coisa se transforma em outra. São os recursos figurativos que dão a tessitura imagética do sonho e da obra literária. O transvasamento dos pensamentos em imagens que ocorrem com bastante frequência nos contos de Poe só ocorre devido ao mecanismo da figurabilidade em imagens visuais. Esse recurso de transformação dos pensamentos em linguagem imagética se deve ao fato de que a figurabilidade é livre da censura do pré-consciente, portanto, "[...] apenas trilha os caminhos que já encontra abertos no pensamento inconsciente" (FREUD, $1900 / 2017$, p. 370) preferindo as transformações do material recalcado sob a forma de imagem e de alusão nos simbolismos.

Dessa maneira, é o infantil (inconsciente) que domina a vida psíquica de Poe e é essa a fonte da sua produção literária com sua monotonia de temas edípicos que sempre remetem a figura do pai, da mãe, ou ainda, as investigações sexuais infantis em torno das diversas partes do corpo dos adultos, sobretudo, dos órgãos sexuais (FREUD, 1908[1976]). Por esse motivo identifico em Edgar Poe um poeta autossimbólico, uma vez que, os simbolismos presentes em seus contos e poemas remetem à sua biografia.

Como o infantil é fonte da produção literária? $\mathrm{Na}$ infância o genital feminino é tomado por um único orifício (teoria cloacal infantil), somente mais tarde a criança fica sabendo que essa região corporal abrange duas cavidades separadas, sejam elas: o ânus e a vagina (FREUD, 1908[1976]). Há também a crença de que todos os adultos possuem um pênis (teoria da mãe fálica), só mais tarde a distinção anatômica entre os 
sexos será simbolizada e compreendida (FREUD, 1924[1996]). Nessa lista também se inclui a teoria sádica do coito, em que a criança na condição de testemunha do ato sexual entre os pais (cena originária) elabora o credo de que o ritmo da cópula imprime dor ou sofrimento a uma das partes envolvidas, geralmente a mãe, quanto ao pai, permanece como sendo o agressor. Desse modo, na obra de Poe encontramos muitas dessas representações infantis, por exemplo, é flagrante a equivalência simbólica entre ouro e fezes no conto $\mathrm{O}$ escaravelho de ouro (POE, 1889), que remete às antigas lembranças de investigação anal do corpo materno (FREUD, 1917/1980) em que a secreção do leite faz com que a criança estabeleça a equivalência entre o dom primitivo das fezes com o dom primitivo do amor maternal (BONAPARTE, 1932b). Retomaremos a análise desse conto logo a seguir. Ao longo da obra literária de Poe, encontramos a liberação de sua fixação infantil de natureza sado-necrófila (BONAPARTE, 1933c). O sadismo de Poe é explicado pelo processo de identificação clássica que acometem os meninos ao identificar-se com a figura do pai e graças à teoria sádica do coito (FREUD, 1908[1976]) que faz com que o menino (pequeno Poe) se identifique com o pai assassino, representado nas suas tramas com personagens masculinos cruéis e sádicos. Já a presença da necrofilia, apesar de tímida e inibida, está ligada às suas lembranças infantis de sua mãe morta, que ele testemunhou e contemplou com admiração e curiosidade. Podemos pensar que a criação poética de Edgar Poe sublima nos contos o luto, a necrofilia e o sadismo (BONAPARTE, 1952b) experimentado na sua infância. O terror de sua poesia remete ao "[...] terror da tentação muito grande que acomete toda criança, quer seja, o terror generalizado do incesto, o terror que habita o nosso mais profundo íntimo" (BONAPARTE, 1952b, p. 120, tradução nossa) e que toma toda a intensidade visual nos diversos elementos figurativos que compõem seus enredos e personagens.

\section{POE: TERMINOLOGIA, SIMBOLISMO E TRADUÇÃO}

Tanto a terminologia quanto o simbolismo presente nos contos de Poe expressam tanto a qualidade quanto a quantidade de afetos presente em suas histórias macabras. Poe foi um escritor fascinado pelos mistérios, um genuíno entusiasta do enigma e da solução de criptogramas, mexendo de forma inquietante com a imaginação dos seus leitores. É muito rica em detalhes a análise feita por Margarida (1998) dos procedimentos técnicos nas duas traduções de Oscar Mendes, Milton Amado e José Rubens Siqueira do conto O barril de Amontilhado (POE, 1995; 1960). A autora nos lembra que "[...] a tradução é um processo de transferência cultural, cujo papel é determinado não apenas por aptidões e preferências individuais, mas, também pelo momento histórico e pela função que o texto desempenha na cultura de chegada" (MARGARIDA, 1998, p. 72). Desse modo, tomando essas duas 
traduções como exemplos se verifica no período de quase meio século entre uma (em 1960) e outra (em 1995) certa uniformidade nas práticas tradutórias que pensadas quanto à fidelidade ao texto original obedecem em geral aos procedimentos de tradução dos tipos: tradução literal, omissão e transposição. Quanto a essa última a autora nos instrui com inúmeros exemplos, para citar apenas um deles temos: "Original: The thousand injuries of Fortunato I had borne as I best could, but when he ventured upon insult I vowed revenge. Transposição: Suponha eu, enquanto possível, as mil ofensas de Fortunato, mas quando se aventurou ele a insultar-me, jurei me vingar" (MARGARIDA, 1998, p. 74). É importante dizer que essas traduções conseguem captar como no original o mundo sombrio dos personagens de Poe. Cabe lembrar que nesse conto o personagem Fortunato, exímio conhecedor de vinho, será envolvido numa trama de vingança por parte de Montresor, que aproveitará dessa habilidade da vítima. Esse plano de vingança é o eixo dorsal do conto. Poe é muito habilidoso com as palavras e leva por meio de figuras de linguagem como a hipérbole na expressão: the thousand injuries (as mil ofensas) o leitor a assumir uma posição frente ao personagem Montresor. Esse convencimento é justificado pela intensidade da suposta ofensa sofrida pela personagem, tornando o leitor cúmplice das situações de extrema crueldade. Trata-se de um estilo de "estética gótica" (MARGARIDA, 1998, p. 79), portanto, produz efeitos espantosos ao representar temas inusitados. Não podemos nos esquecer que também a ironia é integrada à narrativa durante o longo percurso até o amontilhado, pois, Montresor finge propiciar a Fortunato algumas oportunidades de escapar da terrível morte, convidando-o reiteradas vezes a retornar. Dessa maneira, Poe ao traçar uma história semelhante a um estado psicológico alterado tal como "em um sonho ou pesadelo" (BONAPARTE, 1932a, p. 667, tradução nossa) fundamenta a estrutura dialógica da sua representação. Uma trama que envolve mistério e terror e isso se dissemina nas traduções e na receptividade do leitor brasileiro dos seus contos.

Dentre o seu vasto simbolismo podemos destacar os seus simbolismos maternos ora representado nas figuras da Terra, do mar, da lua, elementos que na interpretação bonaparteana muitas vezes representa o grande desejo de retorno ao corpo materno. A figura da mãe está presente no patrimônio afetivo de todos os humanos, mas, Poe parece brincar de investigar o corpo materno sob um tipo de motivação inconsciente propensa à perversidade. Nas palavras de Bonaparte (1932b) Poe é um poeta "amante dos cadáveres" (p. 277), seus poemas ruminam os enigmas do nascimento e de todo tipo de investigação sexual infantil do corpo materno. Tomando um dos seus contos mais famosos como o "Escaravelho de Ouro" (POE, 1889), observamos o autor brincar com um simbolismo específico, considerado um dos mais antigos da humanidade, que é a equivalência das fezes com o ouro. Em psicanálise podemos dizer que essa equivalência decorre do domínio anal localizado no período pré-genital do desenvolvimento da libido. Os excrementos são o primeiro 
presente que a criança oferece à sua mãe (FREUD, 1917/1980), que ao investigar o corpo e os excrementos do corpo da mãe atribui às fezes da mãe o mesmo valor e riqueza nutritiva que o leite materno. Por isso, a criança oferece suas fezes com tanta dedicação. E um traço indelével dessa concepção permanece na mentalidade dos adultos, nos dizeres de Freud (1917[1980]): "nos produtos do inconsciente (ideias espontâneas, fantasias e sintomas) o conceito de fezes (dinheiro, dádiva) mal se distinguem um do outro e são facilmente intercambiáveis" (p. 160). Então, "]...] a passagem das fezes à ouro se realiza regularmente no inconsciente de cada um de nós" (BONAPARTE, 1932b, p. 287). De fato, muitos contos de Poe apresentam as mesmas raízes inconscientes infantis de investigação do corpo maternal, comportamento típico da primeira infância.

Por sua vez, no conto Gato Negro (POE, 2008) a necrofilia contemplativa de Poe dará expressão a impulsões assassinas e sádicas em cenas cotidianas, porém, muito comoventes, como na casa de campo de Fordham, o bichano de Catarina perambulando em torno de Virgínia. No inverno o fogo estava acabando e o pobre animal muito fraco e cuspindo sangue (como uma pessoa tuberculosa) tinha de permanecer na cama, enquanto o outro bichano não se enroscava nele, como se não quisesse aquecê-lo. Bonaparte (1932a) nos lembra que o gato é um animal que simboliza a mulher ou o feminino e para a autora tanto as lembranças da morte da mãe como da esposa do poeta, que próximas da morte cuspiam sangue, funcionaram como restos de um pesadelo que mobilizou a mente e a alma de Poe no trabalho de escrita desse conto. Ao lermos "Gato Negro", sentimos uma agonia de um tipo de espetáculo sádico de observação de um moribundo. De acordo com Bonaparte (1932a) essa foi provavelmente a mesma agonia que Poe sentiu ao assistir a morte de sua mãe e esposa, ambas tuberculosas, num tipo de "necrofilia contemplativa" (BONAPARTE, 1932a, p. 681, tradução nossa), possibilitando-o poetizar profeticamente nas suas personagens femininas a morte da mãe e da esposa, respectivamente.

\section{CONSIDERAÇÕES FINAIS}

Em conclusão, chamo a atenção do leitor para a presença da obra de Poe no quadro das literaturas estrangeiras no Brasil e ao verificar algumas pesquisas sobre traduções de sua obra para o português é possível compreender como o trabalho dos tradutores ajudam a compor esse quadro. No exame da psicobiografia de Poe (BONAPARTE, 1933a; 1933b; 1958) percebemos que apesar da semelhança entre a criação literária e a criação onírica, a obra literária diferente do sonho prima pela forma estética que permite ao desejo recalcado se manifestar impunemente. No caso analisado, o desejo necrófilo e sádico do poeta americano. É preciso supor uma atividade simbolizadora especial da psique do artista durante o trabalho de elaboração 
literária, que se serviu melhor das diversas simbolizações porque essas satisfazem melhor as exigências do inconsciente em razão de que sua figurabilidade não está submetida à censura. Conclui-se afirmando que na criação poética de Poe é a figurabilidade o mecanismo privilegiado na transformação dos pensamentos em imagens.

\section{REFERÊNCIAS}

AMOUROUX, R. Marie Bonaparte e os meios literários. In: . Marie Bonaparte: entre biologie et freudisme. Rennes: Presses Universitaires de Rennes, 2012.

BACHELARD, G. L'eau et les rêves: essai d'imagination sur la matière. Paris: Librairie José Corti, 1942.

BERTIN, C. A última Bonaparte. Rio de Janeiro: Paz e Terra, 1989.

BONAPARTE, M. Edgar Poe, sa vie son oeuvre, étude psychanalytique. La vie et ses poèmes, 1 vol. Paris: Presses Universitaires de France, 1933 a.

Edgar Poe, sa vie son oeuvre, étude psychanalytique. Les contes: les cycles de la mère, 2 vol. Paris: Presses Universitaires de France, 1933b.

. "La structure psychique d'Edgar Poe". L'hygiène mentale, Paris, vol. 28, p. 193-201, 1933c.

. Edgar Poe, sa vie son oeuvre, étude psychanalytique. Les contes: les cycles du père Poe et l'âme humaine, 3 vol. Paris: Presses Universitaires de France, 1958.

. De l'élaboration et de la fonction de l'oeuvre littéraire. Revue Française de Psychanalyse, Paris, vol. 5, n. 4, p. 649-683, 1932a.

Le scarabée d'or d'Edgar Poe. Revue Française de Psychanalyse, Paris, vol. 5, n. 2, p. 275-293, 1932b.

193-201, 1933c.

La structure psychique d'Edgar Poe. L'hygiène mentale, Paris, vol. 28, p.

- L'Identification d'une fille à sa mère morte. In:

Psychanalyse et anthropologie. Paris: Presses Universitaires de France, p. 88-108, 1952a.

- Deuil, nécrophilie et sadisme. In: Psychanalyse et anthropologie. Paris: Presses Universitaires de France, p. 112-128, $1952 \mathrm{~b}$.

BOTTMANN, D. Alguns aspectos da presença de Edgar Allan Poe no Brasil. Tradução em Revista, São Paulo, vol. 1, p. 01-19, 2010.

BOURGERON, J-P. Marie Bonaparte. Paris: Presses Universitaires de France, 1997. 
FREUD, S. Avant-Propos. In: BONAPARTE, M. Edgar Poe, sa vie son oeuvre, étude psychanalytique. La vie et ses poèmes, 1 vol. Paris: Presses Universitaires de France, 1933.

- A interpretação dos sonhos. Tradução do alemão de Renato Zwick. Porto Alegre, L\&PM, 2017. (Trabalho original publicado em 1900).

- O inconsciente. Edição Standard Brasileira das Obras Psicológicas

Completas de Sigmund Freud. (J. Salomão, trad.,Vol. 14, pp. 191-239). Rio de Janeiro: Imago, 1980. (Trabalho original publicado em 1915).

. O delírio e os sonhos na Gradiva de W. Jesen. In:

Obras

completas. (P. C. de Souza, trad., Vol. 8, pp 13-122) São Paulo: Companhia das Letras, 2015. (Trabalho original publicado em 1907).

. Leonardo da Vinci e uma lembrança de sua infância. In:

Edição standard brasileira das obras psicológicas completas de Sigmund Freud. (L. Salomão, trad., Vol. 11, pp 56-126) Rio de Janeiro: Imago, 1980. (Trabalho original publicado em 1910).

- Notas psicanalíticas sobre um relato autobiográfico de um caso de paranóia (Caso Schreber). In: Edição standard brasileira das obras psicológicas completas de Sigmund Freud. (J. Salomão, trad.,Vol. 12, pp. 81-104). Rio de Janeiro: Imago, 1974. (Trabalho original publicado em 1911).

- Sobre as teorias sexuais infantis. In: Edição standard brasileira das obras psicológicas completas de Sigmund Freud. (J. Salomão, trad., vol. 9, pp. 213-232). Rio de Janeiro: Imago, 1976. (Trabalho original publicado em 1908).

- As transformações do instinto exemplificadas no erotismo anal. In: . Edição standard brasileira das obras psicológicas completas de Sigmund Freud. (J. Salomão, trad., vol. 17, pp. 157-166). Rio de Janeiro: Imago, 1980. (Trabalho original publicado em 1917).

- Algumas conseqüências psíquicas da distinção anatômica entre os sexo.

In: Edição standard brasileira das obras psicológicas completas de Sigmund Freud. (J. Salomão, trad.,Vol. 19, pp. 303-320). Rio de Janeiro: Imago. 1996. (Trabalho original publicado em 1924).

LACAN, J. "O seminário sobre 'A carta roubada". In: . Escritos. Rio de Janeiro: Jorge Zahar Editor, p. 13-66, 1998.

MANDIL, R. Os efeitos da letra: Lacan leitor de Joyce. Rio de Janeiro: Contra Capa, 2003.

. Jacques Lacan no banquete joyciano. Em Tese, Belo Horizonte, vol. 4, p. 11-27, 2000.

MARGARIDA, S. M. A. O barril de amontilhado de Edgar Allan Poe: uma análise contrastiva de três traduções. 1998. 112 f. Dissertação de Mestrado em Letras: Estudos Linguísticos. Faculdade de Letras da UFMG, Belo Horizonte, 1998. 
POE, E. A. O escaravelho de ouro e outros. In: Biblioteca Universal Antiga e Moderna. Tradução de Mécia Mousinho de Albuquerque. Lisboa: Companhia Nacional, vol. 37, 1889.

. Histórias extraordinárias. Tradução de Brenno Silveira e outros, com dezesseis contos. São Paulo: Abril Cultural, 1978.

. O Barril de Amontilhado. In:

A. O escaravelho de Ouro e outras histórias. Seleção e Tradução de José Rubens Siqueira. São Paulo: Editora Ática, 1995. . "A carta roubada". In: . Histórias extraordinárias. São Paulo: Nova Cultural, 2002, p. 203-224. Hedra, 2008.

O gato preto e outros contos. Tradução de Guilherme Braga. São Paulo:

. Os assassinatos da rua Morgue e O escaravelho de ouro. Tradução de Júlio Mendonça. São Paulo: Scipione, 2006.

RICARDOU, J. Problèmes du nouveau Roman. Paris: Le Seuil, 1967.

TODOROV, T. Introdução à Literatura Fantástica. São Paulo: Perspectiva, 2004.

TYTELL, P. La plume et divan. Paris: Aubier, 1982.

Recebido em: 28/11/2019

Aprovado em: 07/12/2019

Publicado em: 19/12/2019 